\title{
PELATIHAN DESAIN GRAFIS UNTUK MENINGKATKAN PEMASARAN PADA CV. LAUTAN MAS
}

\author{
Baringin Sianipar'), Preddy Marpaung(2), Dedi Candro Parulian Sinaga') \\ 1)Teknologi Rekayasa Komputer Jaringan, STMIK Pelita Nusantara, Medan, Sumatera Utara, Indonesia \\ ${ }^{2)}$ Manajemen Informatika, STMIK Pelita Nusantara, Medan, Sumatera Utara, Indonesia \\ Corresponding author : Baringin Sianipar \\ E-mail : aniparbaringin87@gmail.com
}

Diterima 09 Juli 2021, Direvisi 28 Agustus 2021, Disetujui 28 Agustus 2021

\begin{abstract}
ABSTRAK
Diera Digital seperti sekarang ini memiliki skill sebagai seorang Graphic Design sangat dibutuhkan. banyak teknik dalam menggunakan iklan di bidang keilmuan Design Grafis. Jadi dalam Pelatihan Design Grafis ini sangat mendukung dalam menunjang berbagai kebutuhan untuk keperluan bisnis perusahaan. dalam membuat sebuah hasil karya dan design yang bagus merupakan hal yang tidak mudah untuk kita lakukan apalagi jika dalam perusahaan karyawannya tidak memiliki background pendidikan yang sesuai dengan bidang keilmuan ini. Oleh sebab itu diharapkan mitra CV. Lautan Mas setelah pelatihan ini dapat mebuat hasil desain produknya lebih baik lagi, untuk dapat meningkatkan Pemasaran ke HOREKA (Hotel, Restoran, Kantor).
\end{abstract}

Kata Kunci : pelatihan desain grafis; desain grafis; HOREKA; pemasaran.

\begin{abstract}
In this digital era, having skills as a Graphic Designer is very much needed. There are many techniques in using advertising in the field of Graphic Design science. So this Graphic Design Training is very supportive in supporting various needs for the company's business needs. in making a good work and design is not an easy thing for us to do, especially if the employees in the company do not have an educational background that is in accordance with this scientific field. Therefore, it is hoped that CV. Lautan Mas after this training can make better product design results, to be able to increase Marketing to HOREKA (Hotels, Restaurants, Offices).
\end{abstract}

Keywords: graphic design training; graphic design; HOREKA; marketing.

\section{PENDAHULUAN}

Dalam Perkembangan Teknologi informasi dan komunikasi pada jaman ini telah berkembang sangat pesat dan telah mempengaruhi semua aspek kehidupan manusia. Diera teknologi informasi ini ditandai dengan kecepatan dan kemudahan untuk mendapatkan informasi yang dibutuhkan. Perkembangan ini sangat berpengaruh kepada perusahaan mikro. Perusahaan mikro saat ini telah melakukan banyak peningkatan dalam hal pemasaran produk termasuk salah satunya adalah pelayanan dalam hal pemberian informasi. Informasi yang diberikan sangat membantu perusahaan untuk itu perlu adanya peningkatan sumber daya manusia di perusahaan untuk meningkatkan pemasaran.

Desainer grafis (bahasa Inggris: graphic designer) adalah profesi yang berhubungan dengan ilustrasi, tipografi, fotografi, atau graphic motion/gambar bergerak/ animasi. Seorang desain grafis membuat karya untuk penerbit salah satunya yaitu media cetak, elektronik, brosur dan iklan suatu produk. Para desain grafis bertanggung jawab dalam membuat sebuah tampilan agar tampak menarik, yang bisa ditampilan dan diaplikasikan dalam berbagai bentuk materi promosi yang berkaitan dengan produk dan publik. Para desain grafis bertugas untuk membuat dan menyampaikan sebuah informasi yang diinginkan oleh produk/klien dalam bentuk desain yang menarik sesuai permintaan klien.

CV. Lautan Mas merupakan salah satu perusahaan yang bergerak dibidang perikanan dengan fokus kegiatannya adalah untuk melayani pelanggan atau Pembeli melalui pelayanan yang berkualitas. Oleh sebab itu perusahaan harus mulai memikirkan peningkatan pemasaran produk ke HOREKA (Hotel, Restoran, Kantor).

Peningkatan Pemasaran hasil produk CV. Lautan Mas sangat dibutuhkan saat ini. Oleh sebab itu mitra ingin meningkatkan sumberdaya manusia dalam pelatihan disain grafis agar dapat meningkatkan pemasaran produk ke HOREKA (Hotel, Restoran, Kantor). 
Adapun yang menjadi solusi dari pelatihan ini adalah memberikan pemahaman dan keterampilan Desain Grafis dalam pembuatan media promosi kepada manajemen maupun karyawan CV. Lautan Mas. Diharapkan setelah kegiatan Pengabdian Kepada Masyarakat ini maka karyawan CV. Lautan Mas dapat melalukan promosi dengan membuat Marchandise, membuat logo produk, hingga poster iklan digital untuk dapat meningkatkan Pemasaran ke HOREKA (Hotel, Restoran, Kantor).

Berikut ini adalah lokasi kegiatan dilaksanakan di CV. Lautan Mas, Jalan Sei Brantas No. 81, Kelurahan Babura Sunggal, Kecamatan Medan Sunggal, Kota Medan, Provinsi Sumatera Utara.

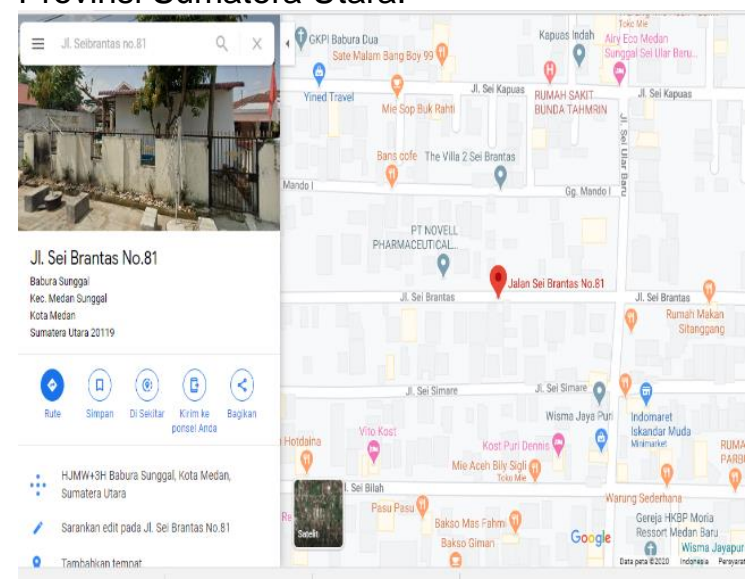

Gambar 1. Lokasi CV. Lautan Mas

\section{METODE}

Dalam melakukan pelaksanaan pengabdian masyarakat, kegiatan ini dilakukan beberapa tahapan sebagai berikut:

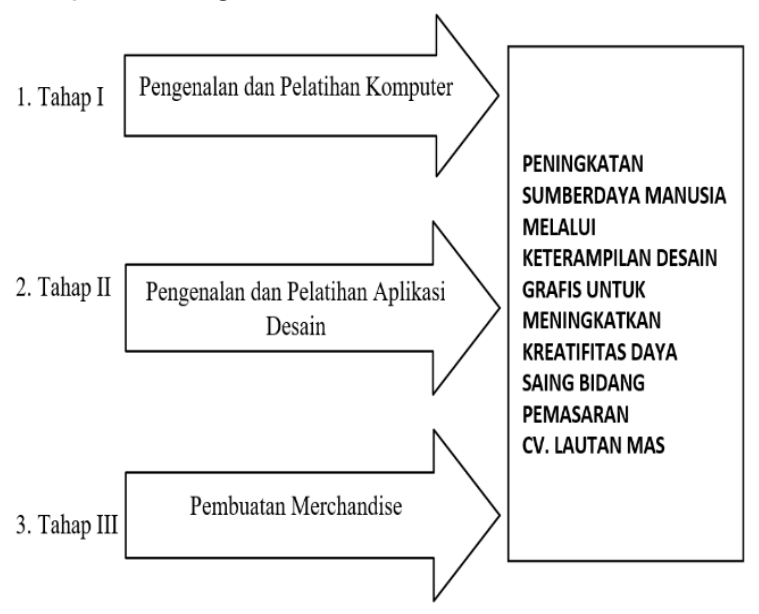

Gambar 2. Metode pelaksanaan pengabdian masyarakat

Penjelasan Mekanisme Pelaksanaan Kegiatan: 1. Tahap ke-1 yaitu pengenalan dan pelatihan komputer, pada tahap ini peserta akan diberikan pemahaman tentang pemakaian dan kegunaan dari komputer itu sendiri. Di tahap ini peserta juga diberikan pemahaman mengenai spesifikasi minimal dari perangkat keras atau hardware yang dibutuhkan dalam pelatihan desain ini.

2. Tahap ke-2 yaitu pengenalan dan pelatihan aplikasi desain grafis, peserta diberikan pemahaman mengenai aplikasi yang tidak berbayar dan juga aplikasi berlisensi. Pemahaman ini perlu diberikan agar peserta mengetahui perbedaan antara aplikasi opensource yang digratiskan dan juga mengetahui aplikasi yang berlisensi, sehingga peserta dari CV. Lautan Mas mampu memahami kelebihan dan kekurangan dalam penggunaan aplikasi desain tersebut terutama fitur-fitur yang dimilikinya.

3. Tahap ke-3 yaitu pembuatan desain, beberapa desain yang dihasilkan dapat berupa logo produk atau poster iklan digital. Lalu pada tahap akhir desain yang telah mereka buat diharapkan dapat berupa sebuah merchandise. Merchandise ini dibuat sebagai salah satu pendapatan yang akan mereka peroleh.

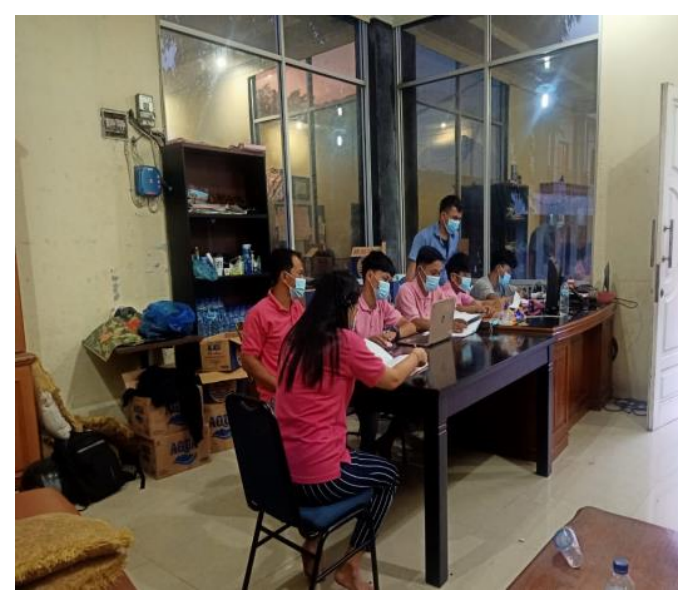

Gambar 3. Memberikan penjeasan tentang desain grafis (Sumber: Data Penulis)

Tabel 1. Kegiatan Pelaksanaan Pengabdian

\begin{tabular}{|c|c|c|c|c|}
\hline Hari & Tanggal & No & Waktu & Keterangan \\
\hline \multirow{4}{*}{ Sabtu } & \multirow{4}{*}{$\begin{array}{l}01 \text { May } \\
2021\end{array}$} & 1 & $\begin{array}{l}\text { 09.00- } \\
10.00 \\
\text { Wib }\end{array}$ & $\begin{array}{l}\text { Pembukaan, Penjelasan dan } \\
\text { tahapan pelaksanaan } \\
\text { kegiatanpelatihan, } \\
\text { pengenalan dan } \\
\text { pelatihan komputer }\end{array}$ \\
\hline & & 2 & $\begin{array}{l}10.00- \\
12.00\end{array}$ & $\begin{array}{l}\text { pengenalan dan pelatihan } \\
\text { aplikasi desain grafis }\end{array}$ \\
\hline & & & Wib & \\
\hline & & 3 & $\begin{array}{l}12.00- \\
13.30\end{array}$ & $\begin{array}{l}\text { ISOMA (Istirahat, Sholat, dan } \\
\text { Makan Siang) }\end{array}$ \\
\hline
\end{tabular}


4 13.30- Pembuatan Merchandise 15.30

5 15.30- Penutupan

16.00

\section{HASIL DAN PEMBAHASAN}

Hasil pelaksanaan program pengabdian masyarakat ini dilihat dari beberapa aspek sebagai berikut :

1. Adanya tanggapan yang positif dari peserta pelatihan di CV. Lautan Mas. Tanggapan peserta pelatihan akan diukur melalui observasi selama kegiatan pelatihan berlangsung dan juga pesan, saran, kritik dan usulan dari peserta pelatihan terhadap program pengabdian masyarakat ini.

2. Berkembangnya keterampilan peserta CV. Lautan Mas setelah mengikuti pelatihan dan Keterampilan peserta pelatihan akan diobservasi saat pelatihan melalui pemberian contoh/gambaran tugas atau simulasi dalam mendesain gambar produk selama pelatihan dan selama proses pendampingan.

3. Setiap peserta yang terlibat dalam pelatihan ini diharapkan mampu membuat desain pruduk dengan baik sesuai dengan contoh yang dibuat serta dapat mengembangkan contoh simulasi yang ada.

\section{Pembahasan}

Selama pelaksanaan program pelatihan ini, mulai dari tahap persiapan sampai pelaksanaannya, dapat disampaikan temuantemuan sebagai berikut:

Selama pelaksanaan program pelatihan ini, mulai dari tahap persiapan sampai pelaksanaannya, dapat disampaikan temuantemuan sebagai berikut:

1. Keikutsertaan para peserta dalam pelatihan sangat tinggi, menyambut dengan baik dalam program pengabdian masyarakat ini. Pihak CV. Lautan Mas berharap program ini bisa dilaksanakan di tahun-tahun selanjutnya.

2. Materi pelatihan yang diberikan sangat sesuai dengan kebutuhan pihak CV. Lautan Mas dalam mendukung usaha bisnis mereka. Materi ini benar-benar memberikan penyegaran dan penambahan wawasan dan ketrampilan akan pemanfaatan perkembangan teknologi informasi dalam hal Mendisain di Corel Draw dan Photoshop. Adanya permintaan untuk dilakukan kegiatan kedepan dalam penerapan perkembangan teknologi seperti manajemen administrasi dan lain sebagainya.

\section{SIMPULAN DAN SARAN Simpulan}

Dari hasil evaluasi serta temuantemuan yang diperoleh selama pelaksanaan kegiatan pengabdian kepada masyarakat ini, dapat kami simpulkan bahwa program pelatihan ini telah mampu memberikan manfaat yang sangat besar kepada pihak CV. Lautan Mas, dimana hasil akhir pelatihan ini peserta yang diutus pihak Perusahaan sukses membuat desain produk pemasaran dengan menggunakan coreldraw dan photoshop, sehingga hasil desain ini bisa diterapkan dalam Media promosi untuk meningkatkan produk pemasaran perusahaan. Disamping itu juga, pelatihan ini bisa menjadi penyegaran dan tambahan wawasan kepada peserta yang terlibat.

\section{Saran}

dengan hasil evaluasi respon yang telah dilakukan, kami menyarankan hendaknya program-program pengabdian masyarakat seperti ini bisa dilaksanakan secara berlanjut ke tahun tahun yang akan datang.

\section{UCAPAN TERIMAKASIH}

Dalam Pelaksanaan kegiatan Pengabdian Kepada Masyarakat ini sudah melibatkan banyak pihak yang sudah berkontribusi, oleh sebab itu dalam kesempatan ini kami tim Pengabdi mengucapkan terima kasih dan penghargaan kepada :

1. PPM STMIK Pelita Nusantara selaku mengkoordinasi pelaksanaan pengabdian kepada masyarakat secara melembaga, baik secara administratif.

2. Manajemen CV. Lautan Mas yang telah memberikan ijin dan berpartisipasi dalam pelaksanaan kegiatan pengabdian.

\section{DAFTAR RUJUKAN}

Wahyuningsih, Delpiah, dkk. (2019). Pelatihan Website untuk Meningkatkan Kemampuan Siswa SMPN9 dalam Menghadapi Era Industri 4.0. Seminar Nasional Pengabdian Masyarakat (SNPMas) STMIK Dipanegoro Makasar:314-319.

Adinata, I Wayan, dkk. (2015). Pengembangan Komik Pembelajaran Fisika Berbasis Desain Grafis. Jurnal Pembelajaran Fisika (JPF). Vol 3 (No 5): 109-117.

Nugrahani, Rahina. (2015). Peran Desain Grafis Pada Label dan Kemasan Produk Makanan UMKM. Jurnal Imajinasi. Vol 9 (No 2): 127-136.

Dewojati, R. K. W. (2015) 'Desain Grafis Sebagai Media Ungkap Periklanan', 
Imaji, 7(2). doi: 10.21831/imaji.v7i2.6633.

Rahmat, S. T. (2015) 'Pemanfaatan Multimedia Interaktif Berbasis Komputer Dalam Pembelajaran', Jurnal Pendiikan dan Kebudayaan Missio, 7(2), pp. 196-208.

Ryza, M., Spd, S. and Kom (2014) 'Berbasis Multimedia Interaktif', Jurnal Mahasiswa STEKOM Semarang, 1(1). Available at: https://www.neliti.com/id/publications/1 904 79/media-pembelajaran-desaingrafis-disma-1-kudus-berbasismultimedia-interaktif. 